\title{
Using Recycled Glass and Zeolite in Concrete Pavement to Mitigate Heat Island and Reduce Thermal Cracks
}

\author{
Erhan Burak Pancar \\ Department of Architecture, Ondokuz Mayıs University, 55100 Samsun, Turkey \\ Correspondence should be addressed to Erhan Burak Pancar; erhanpancar@hotmail.com
}

Received 22 April 2016; Accepted 15 June 2016

Academic Editor: Joao M. L. Reis

Copyright ( 2016 Erhan Burak Pancar. This is an open access article distributed under the Creative Commons Attribution License, which permits unrestricted use, distribution, and reproduction in any medium, provided the original work is properly cited.

\begin{abstract}
Urban heat island (UHI) effect is built environmental issue related to pavements. It is desired to reduce pavement high surface temperature in summer to mitigate UHI effect. High surface temperature also affects slab temperature difference (the top surface temperature minus the bottom surface temperature of the slab). The increased slab temperature difference induces a high possibility of cracking in concrete roads. The prime aim of this study was to reduce the slab surface temperature by using recycled glass as a fine aggregate and zeolite as cement in concrete. Recycled glass was used to replace fine aggregate in proportions of $10 \%, 20 \%$, and $30 \%$ by total weight of aggregate. Zeolite replaced Portland cement in proportions of $10 \%$ and $30 \%$ for three different proportions of recycled glass concrete mixtures. Optimum proportions were determined by examining mechanical properties of samples and alkali-silica reactions. It was noticed that using recycled glass and zeolite together in concrete reduces pavement surface temperature and temperature gradient in summer.
\end{abstract}

\section{Introduction}

Built environmental issue related to pavements is the urban heat island (UHI) effect. Heat islands can be considered as surface and atmospheric heat islands $[1,2]$. Hot pavements contribute to the heat island effect. Surface heat islands can affect human thermal comfort and air quality. $70-80^{\circ} \mathrm{C}$ surface temperatures on pavements have been measured on hot summer days in Phoenix, Arizona [3]. As one major thermal characteristic, solar reflectivity or albedo (1-solar absorptivity) is an indicator of the reflecting power of a surface. It is defined as the ratio of the reflected solar radiation to the incident solar radiation at the surface. It is dimensionless fraction and is measured on a scale from 0 to 1 . Albedo of 0 means no reflecting power and albedo of 1 means perfect reflection [4]. Increasing the solar reflectivity of a pavement surface by using surfacing materials of light colour or applying light colour coating on dark surfacing materials can lower the pavement surface temperature [5-8]. Solar reflective materials can be identified as one of the most promising solutions to counteract urban heat island [9].

Portland cement concrete (PCC) pavements are affected by temperature differences. The temperature at the top surface of the slab is higher than that of the bottom during the day. The top tends to expand while the bottom tends to contract. The temperature at the top surface of the slab is lower than that of the bottom at night and the top tends to contract. Kuo [10] recommended using loading at the centre of the slab during the daytime and loading at the edge of the slab at nighttime in analysing of concrete pavement. Negative temperature gradient (nighttime) is not taken into account especially at concrete road design in Germany. This is because negative gradient is less than positive gradient (daytime) [11].

Thermal conductivity is used to estimate the temperature gradient of concrete pavement [12]. Temperature gradient is the uniform flow of heat in a specific sample from one side to the other. Temperature gradients throughout the slab thickness play a key role in calculating thermal stresses in PCC pavements, known as curling [13]. Decreasing the thermal conductivity of concrete also decreases the temperature gradient of concrete road and reduces thermal cracks in concrete slab. It is necessary to decrease the curling stresses resulting from the fluctuation of temperature gradients.

Aggregate type, percent of cement paste, coarse aggregate, fine aggregate, porosity, supplementary cementitious materials (SCMs), moisture, and temperature of local environment 
are some of the factors that affect the thermal conductivity of concrete [13-16]. Researches done before investigated that mixes with a high fine aggregate proportion had a higher thermal conductivity compared to a high proportion of coarse aggregate $[14,17]$. The use of structures with high thermal resistance has become of great importance in hot weather countries where temperature can reach high levels especially in summer [18]. The low value of thermal conductivity is desirable due to the associated ability to provide thermal insulation [19].

This study mainly focuses on reducing the temperature gradient that causes thermal cracks in concrete road and also mitigates heat island. The effects of different proportions of recycled glass and zeolite used as a fine aggregate and Portland cement, respectively, were investigated. Compressive strength, flexural strength, and alkali-silica reaction (ASR) for the determined proportion of materials were investigated. The slab temperatures were measured at various depths of three different types of pavements to control the effects of recycled glass and zeolite on temperature gradient of concrete road. Pavement surface temperatures were measured in summer for different types of concrete mixtures. Ideal concrete mixture which had lower surface temperature was determined.

\section{Glass and Zeolite in Concrete}

Water absorption capacity of glass is almost zero and when it is used as an aggregate in concrete, it decreases the water absorption and drying shrinkage values which is a desired property for concrete [20]. ASR occurs in concrete when alkalis from cement react with free silica presented in certain aggregates to form alkali-silica gels [21]. This phenomenon reduces the service life of the affected structure. Glass has a higher value of $\mathrm{SiO}_{2}$ and Lam et al. [20] observed whether ASR expansion would be seen or not in concrete with glass in its mix design when there is enough moisture. It was observed that if the proportion of the glass is lower than $25 \%$ weight of the aggregate in concrete, ASR expansions are in negligible level. Byars et al. [22] determined that the reactivity of glass particles generally increases with particle size from around $1-2 \mathrm{~mm}$. Glass particles below this size appear to reduce the propensity for ASR in larger glass particles. Ready-mixed concrete made with glass pozzolan and/or glass sand showed increasing in strength development to 1 year, indicating a pozzolanic contribution from the fine glass particles. Krishnamoorthy and Zujip [23] determined that using recycled glass as fine aggregate decreases thermal conductivity of concrete.

Zeolite is a natural or synthetic hydrated aluminosilicate mineral of alkali and alkaline earth metal with an open three-dimensional crystal structure. Zeolite concrete is much less frequent subject of investigation as compared with fly ash, silica fume, or ground granulated blast furnace slag as SCMs. The most significant effects of using zeolite as cement in concrete are reduction in expansion due to alkali-silica reaction, resistance to acid and sulfate attacks, and pozzolanic consumption of calcium hydroxide component of Portland cement hydration in the paste. The performance of natural zeolite in mortar/concrete has been compared with performance of other pozzolanic materials [24-26]. Poon et al. [25] determined that the degree of reaction of natural zeolite in a paste with a higher percentage of replacement is lower than in a paste with a lower percentage of replacement. Chan and $\mathrm{Ji}$ [26] noticed that pozzolanic reactivity of natural zeolite is between pulverized fuel ash and silica fume. Kilınçarslan [27] determined that using zeolite as Portland cement decreases the thermal conductivity of concrete.

\section{Pavement Surface Temperature}

Li et al. [4] investigated the effect of albedo on concrete pavement surface temperature and they determined that surface temperatures were $44^{\circ} \mathrm{C}, 50^{\circ} \mathrm{C}$, and $59^{\circ} \mathrm{C}$ for concrete mixtures with an albedo of $0.29,0.26$, and 0.18 , respectively. The effects of thermal conductivity and heat capacity were assumed identical in that study. Qin and Hiller determined that maximum thermal tensile stress of a slab can increase up to $0.3 \mathrm{MPa}$ when the pavement surface's solar absorptivity rises from 0.65 to 0.85 [28]. Although this stress value can be assumed as small, after combining with external loadings from traffic, it makes the total stress of a slab close to the flexure tensile strength.

When the albedo of the concrete surface is high and the thermal conductivity of the concrete is low, the temperature fluctuations of the pavement surface will be in minimum during a day and temperature gradient will be reduced. This will also reduce thermal cracks on concrete road and lower surface temperature will mitigate heat island.

Sand as a fine aggregate has a good thermal conductivity and if the material used as sand in concrete does not cause ASR and if that material has a lower thermal conductivity than the sand, curling stress will reduce at the concrete pavement slab. Also, this reduction can be obtained by replacing Portland cement with a material which has a lower thermal conductivity. Pancar and Akpinar [29] used glass beads as a fine aggregate in concrete road and they obtained lower surface temperature in summer while the albedo was the same. The concrete pavement surface temperature decreased $12.5^{\circ} \mathrm{C}$ by using glass bead in their study. If the alternative materials used as fine aggregate and Portland cement have lighter colour than fine aggregate and Portland cement used in control mixture, the albedo will also increase and this property will also help to decrease the pavement surface temperature in summer.

\section{Methods}

Ten different types of mixtures were designed to study the effects of recycled glass and natural zeolite on compressive strength, flexural strength, and ASR of the concrete. One of these mixtures was a control mixture and three of the mixtures had $10 \%, 20 \%$, and $30 \%$ proportions of recycled glass by total weight of aggregates. Six different mixtures with different proportions (10\% and 30\%) of zeolite for each recycled glass sample proportion were also prepared. All coarse and fine aggregates were limestone in control mix design. Fine aggregates are more effective in thermal conductivity 
TABLE 1: Mixture design of concrete samples.

\begin{tabular}{|c|c|c|c|c|c|c|c|c|}
\hline Mixtures & $\begin{array}{c}\text { Cement PC } \\
42.5(\mathrm{Kg}) \\
\end{array}$ & Water (lt) & $\begin{array}{c}\text { Recycled } \\
\text { glass }(\mathrm{Kg})\end{array}$ & $\begin{array}{l}\text { Zeolite } \\
(\mathrm{Kg})\end{array}$ & $\begin{array}{c}0-5 \mathrm{~mm} \text { fine } \\
\text { aggregate }(\mathrm{Kg})\end{array}$ & $\begin{array}{l}5-12 \mathrm{~mm} \text { coarse } \\
\text { aggregate }(\mathrm{Kg})\end{array}$ & $\begin{array}{c}13-22 \text { coarse } \\
\text { aggregate }(\mathrm{Kg})\end{array}$ & $\begin{array}{c}\text { Admixture } \\
\text { (gr) }\end{array}$ \\
\hline Standard mixture & 7.70 & 3.85 & 0 & 0 & 20.22 & 8.80 & 12.32 & 80 \\
\hline G10Z0 & 7.70 & 3.85 & 4.13 & 0 & 16.09 & 8.80 & 12.32 & 80 \\
\hline G10Z10 & 6.93 & 3.85 & 4.13 & 0.77 & 16.09 & 8.80 & 12.32 & 80 \\
\hline G10Z30 & 5.39 & 3.85 & 4.13 & 2.31 & 16.09 & 8.80 & 12.32 & 80 \\
\hline G20Z0 & 7.70 & 3.85 & 8.27 & 0 & 11.95 & 8.80 & 12.32 & 80 \\
\hline G20Z10 & 6.93 & 3.85 & 8.27 & 0.77 & 11.95 & 8.80 & 12.32 & 80 \\
\hline G20Z30 & 5.39 & 3.85 & 8.27 & 2.31 & 11.95 & 8.80 & 12.32 & 80 \\
\hline G30Z0 & 7.70 & 3.85 & 12.40 & 0 & 7.82 & 8.80 & 12.32 & 80 \\
\hline G30Z10 & 6.93 & 3.85 & 12.40 & 0.77 & 7.82 & 8.80 & 12.32 & 80 \\
\hline G30Z30 & 5.39 & 3.85 & 12.40 & 2.31 & 7.82 & 8.80 & 12.32 & 80 \\
\hline
\end{tabular}

TABLE 2: Sieve analysis of recycled glass as a fine aggregate.

\begin{tabular}{lc}
\hline Sieve size $(\mathrm{mm})$ & Percentage passing by weight $(\%)$ \\
\hline$<0.125$ & 0.0 \\
0.125 & 1.7 \\
0.160 & 3.8 \\
0.250 & 14.7 \\
0.315 & 23.1 \\
0.500 & 63.0 \\
0.630 & 86.6 \\
1.000 & 100.0 \\
\hline
\end{tabular}

TABLE 3: Sieve analysis of standard fine aggregate.

\begin{tabular}{lc}
\hline Sieve size $(\mathrm{mm})$ & Percentage passing by weight $(\%)$ \\
\hline$<0.063$ & 0.0 \\
0.063 & 11.5 \\
0.250 & 32.6 \\
0.500 & 41.0 \\
1.000 & 52.8 \\
2.000 & 72.7 \\
4.000 & 100.0 \\
\hline
\end{tabular}

than coarse aggregates. Due to this reason, recycled glass was used as a fine aggregate to obtain lower slab temperatures in this study. Aggregates used in this study were limestone and Portland cement $42.5 \mathrm{R}$ was used in all mixtures. The mixtures were named using the type and percentage of recycled glass and zeolite in the concrete mixtures. For example, G10Z0 represents the concrete mixture that consists of $10 \%$ proportion of recycled glass by total weight of aggregate and $0 \%$ proportion of zeolite in cement. Water/cement ratio was 0.50 in all blends. Standard $15 \mathrm{~cm} \times 15 \mathrm{~cm} \times 15 \mathrm{~cm}$ cube C30/37 strength class concrete specimens were prepared for the testing program. Mixture designs of the concrete samples are in Table 1. Sieve analysis of recycled glass, used as a fine aggregate, and standard fine aggregate are in Tables 2 and 3, respectively. Chemical properties of fine aggregate, recycled glass, zeolite, and Portland cement are in Table 4.
The potential ASR expansion of the prepared mortar bars $(25 \times 25 \times 285 \mathrm{~mm})$ with a water to cement ratio of 0.47 was assessed in accordance with ASTM C1260 [30]. Ten series of mortar bars were prepared in total. In these series, three different proportions $(10 \%, 20 \%$, and $30 \%)$ of recycled glass and two different proportions (10\% and $30 \%)$ of zeolite for each recycled glass sample were prepared with control mixture. The test period was 28 days. The result of mortar bars test is shown in Figure 1. ASR expansion needs to meet the requirements prescribed in ASTM C1260 ( $<0.1 \%$ within 14 days). Mixture proportions of mortar bars are in Table 5.

Compressive and flexural strength measurements were done for all samples at 28 and 90 days. The compressive strength values need to be at least $37 \mathrm{MPa}$ at 28 -day measurement for C30/37 type of concrete. After ASR and compressive strength measurements, some mixture samples were eliminated and temperature measurements of concrete road were made for ideal mixtures. In order to monitor the temperature profiles during the day, temperature sensors were installed at every $5 \mathrm{~cm}$ depth of 3 different types of $25 \mathrm{~cm}$ thick concrete slabs. The length and width of the slabs were $1 \mathrm{~m}$ and $1.5 \mathrm{~m}$, respectively.

\section{Results}

It was observed that all samples used in this study were able to meet the ASR expansion requirements. Using recycled glass, smaller than $1 \mathrm{~mm}$, as fine aggregate increases the expansions after 14 days and using zeolite as Portland cement significantly decreases the expansions of mixtures with recycled glass. ASR test results for ten different types of mixtures are in Figure 1.

Compressive and flexural strength of ten different types of mixtures for 28 and 90 days are in Table 6. G30Z0, G30Z10, and G30Z30 mixtures did not meet the compressive strength requirements of $\mathrm{C} 30 / 37$ type of concrete and these mixtures were eliminated for the temperature gradient measurements.

After ASR and compressive strength measurements, it was observed that the standard mixture, G20Z0 mixture, and G20Z30 mixture were suitable for temperature gradient measurements and these measurements were done on these samples. Before measuring temperature gradients on the site, thermal conductivities of standard mixture, G20Z0 mixture, 
TABLE 4: Chemical properties of fine aggregate, recycled glass, zeolite, and Portland cement.

\begin{tabular}{lcccc}
\hline Oxide & Fine aggregate & Recycled glass & Zeolite & Portland cement 42.5 R \\
\hline $\mathrm{SiO}_{2}(\%)$ & 2.59 & 71.72 & 68.81 & 22.55 \\
$\mathrm{Al}_{2} \mathrm{O}_{3}(\%)$ & 1.09 & 0.92 & 14.17 & 7.12 \\
$\mathrm{CaO}(\%)$ & 95.09 & 8.50 & 1.91 & 61 \\
$\mathrm{MgO}(\%)$ & - & 4.22 & 1.10 & 3.56 \\
$\mathrm{Fe}_{2} \mathrm{O}_{3}(\%)$ & 0.92 & 0.11 & 1.84 & 3.81 \\
$\mathrm{~K}_{2} \mathrm{O}(\%)$ & 0.17 & 0.45 & 3.40 & 0.12 \\
$\mathrm{Na}_{2} \mathrm{O}(\%)$ & - & 13.78 & - & - \\
\hline
\end{tabular}

TABLE 5: Mixture proportions of mortar bars.

\begin{tabular}{lccccc}
\hline Mixtures & Cement (gr) & Water (gr) & Fine aggregate (gr) & Zeolite (gr) & Recycled glass (gr) \\
\hline Control mixture & 440 & 207 & 990 & - & - \\
G10Z0 & 440 & 207 & 900 & 44 & 90 \\
G10Z10 & 396 & 207 & 900 & 132 & 90 \\
G10Z30 & 308 & 207 & 900 & - & 44 \\
G20Z0 & 440 & 207 & 800 & 132 & 200 \\
G20Z10 & 396 & 207 & 800 & - & 200 \\
G20Z30 & 308 & 207 & 600 & 44 & 300 \\
G30Z0 & 440 & 207 & 600 & 600 & 300 \\
G30Z10 & 396 & 207 & & 300 \\
\hline
\end{tabular}

and G20Z30 mixture concrete were measured by using the Testo-635 product. Thermal conductivities were determined as $2.57 \mathrm{~W} / \mathrm{m} \cdot \mathrm{K}, 2.2 \mathrm{~W} / \mathrm{m} \cdot \mathrm{K}$, and $2.08 \mathrm{~W} / \mathrm{m} \cdot \mathrm{K}$ for standard mixture, G20Z0 mixture, and G20Z30 mixture, respectively. One of the slabs was standard concrete mixture type and the others were G20Z0 and G20Z30 types of concrete. The sensors were installed at the middle of the slabs and the slabs were on $25 \mathrm{~cm}$ thick crushed limestone base course layer. The slab temperatures at various depths were measured between 08:00 AM and 6:00 PM in August. Temperature measurements are in Figures 2, 3, and 4 for three different types of concrete slabs.

It is observed from Figure 2 that the highest temperature measurement of the top surface of the control mixture slab was at 2:00 $\mathrm{PM}$ and it was $50.0^{\circ} \mathrm{C}$. The biggest temperature difference on top surface of the slab was $20.0^{\circ} \mathrm{C}$ during the testing time. The biggest temperature difference on bottom of the slab was $4.0^{\circ} \mathrm{C}$ during the testing time. The biggest temperature difference between the top and bottom surface of the slab was $14.0^{\circ} \mathrm{C}$ at 2:00 PM. The bottom surface temperatures changed in the range of $34^{\circ} \mathrm{C}-38^{\circ} \mathrm{C}$ during the measurement time.

It is observed from Figure 3 that the highest temperature measurement of the top surface of the G20Z0 mixture slab was at 2:00 $\mathrm{PM}$ and it was $41.0^{\circ} \mathrm{C}$. The biggest temperature difference on top surface of the slab was $13.0^{\circ} \mathrm{C}$ during the testing time. The biggest temperature difference on bottom of the slab was $4.0^{\circ} \mathrm{C}$ during the testing time. The biggest temperature difference between the top and bottom surface of the slab was $7.0^{\circ} \mathrm{C}$ at 2:00 PM. The bottom surface temperatures changed in the range of $30^{\circ} \mathrm{C}-34^{\circ} \mathrm{C}$ during the measurement time.
It is observed from Figure 4 that the highest temperature measurement of the top surface of the G20Z30 mixture slab was at 2:00 PM and it was $38.0^{\circ} \mathrm{C}$. The biggest temperature difference on top surface of the slab was $10.0^{\circ} \mathrm{C}$ during the testing time. The biggest temperature difference on bottom of the slab was $3.0^{\circ} \mathrm{C}$ during the testing time. The biggest temperature difference between the top and bottom surface of the slab was $5.0^{\circ} \mathrm{C}$ at 2:00 PM. The bottom surface temperatures changed in the range of $30^{\circ} \mathrm{C}-33^{\circ} \mathrm{C}$ during the measurement time.

\section{Discussion}

It is observed from Figure 5 that the surface temperature of standard mixture is higher than G20Z0 mixture between 8:00 $\mathrm{AM}$ and 6:00 PM and the surface temperature of G20Z0 mixture is higher than G20Z30 mixture between 10:00 AM and 6:00 PM. Using recycled glass in proportion of $20 \%$ by total weight of aggregate decreases the biggest surface temperature of concrete pavement from $50^{\circ} \mathrm{C}$ to $41^{\circ} \mathrm{C}$ at 2:00 PM. Replacing zeolite with Portland cement in proportion of $30 \%$ in this type of recycled concrete mixture decreases the biggest surface temperature $3^{\circ} \mathrm{C}$ more.

Top and bottom surface temperature differences measured for three concrete samples are in Figure 6. It is observed that these differences are very close to $0^{\circ} \mathrm{C}$ at 10:00 AM and 5:00 PM. Top and bottom surface temperature differences are increasing between these hours and come to the highest point at 2:00 PM for three samples. The biggest top and bottom surface temperature difference is $14^{\circ} \mathrm{C}, 7^{\circ} \mathrm{C}$, and $5^{\circ} \mathrm{C}$ for standard sample and G20Z0 and G20Z30 samples, respectively. 


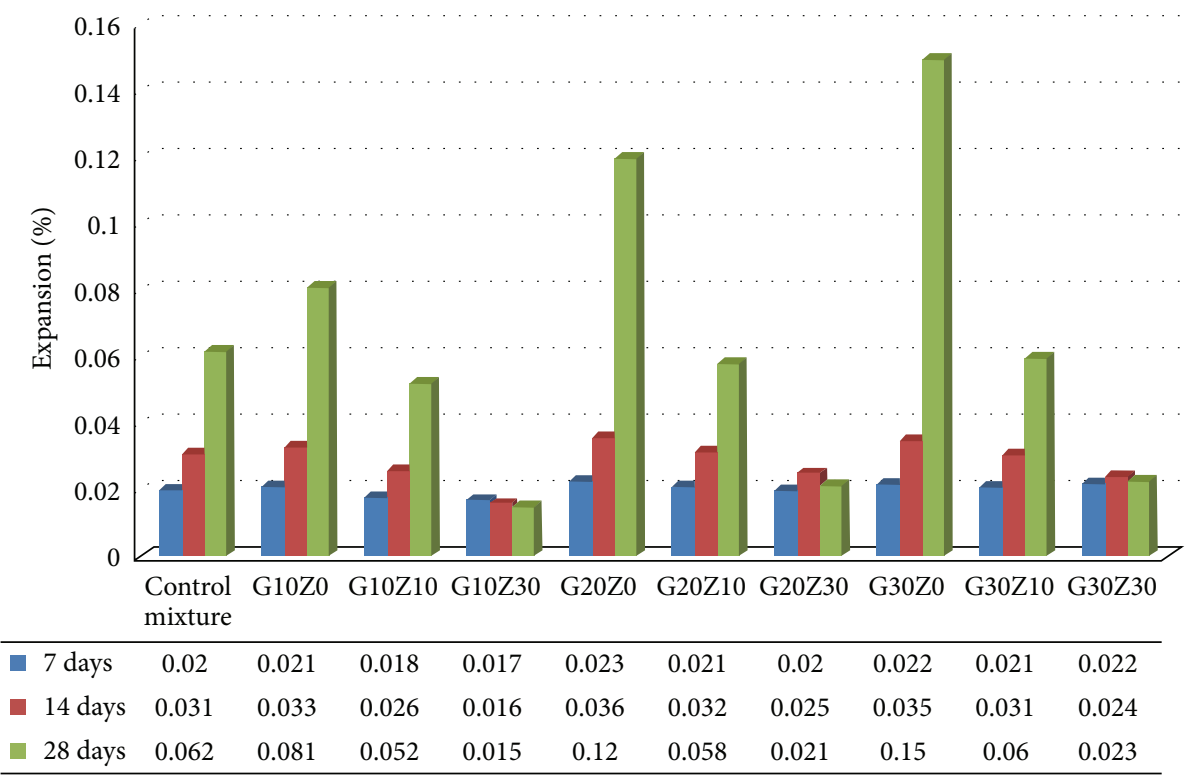

FIGURE 1: ASR test results for samples.

TABLE 6: Compressive and flexural strength of samples.

\begin{tabular}{lcccc}
\hline Mixtures & $\begin{array}{c}\text { 28-day compressive } \\
\text { strength (MPa) }\end{array}$ & $\begin{array}{c}\text { 90-day compressive } \\
\text { strength (MPa) }\end{array}$ & $\begin{array}{c}\text { 28-day flexural } \\
\text { strength (MPa) }\end{array}$ & $\begin{array}{c}\text { 90-day flexural } \\
\text { strength (MPa) }\end{array}$ \\
\hline Standard mixture & 38.8 & 48.4 & 4.26 & 5.35 \\
G10Z0 & 38.25 & 47.86 & 4.53 & 5.36 \\
G10Z10 & 40.15 & 49.56 & 4.65 & 5.45 \\
G10Z30 & 37.11 & 47.92 & 4.51 & 5.28 \\
G20Z0 & 40.28 & 53.72 & 4.98 & 5.75 \\
G20Z10 & 41.06 & 55.13 & 5.07 & 5.88 \\
G20Z30 & 38.22 & 54.01 & 4.89 & 5.72 \\
G30Z0 & 30.72 & 40.63 & 3.94 & 4.48 \\
G30Z10 & 30.61 & 42.06 & 3.96 & 4.47 \\
G30Z30 & 28.12 & 40.62 & 3.78 & 4.44 \\
\hline
\end{tabular}

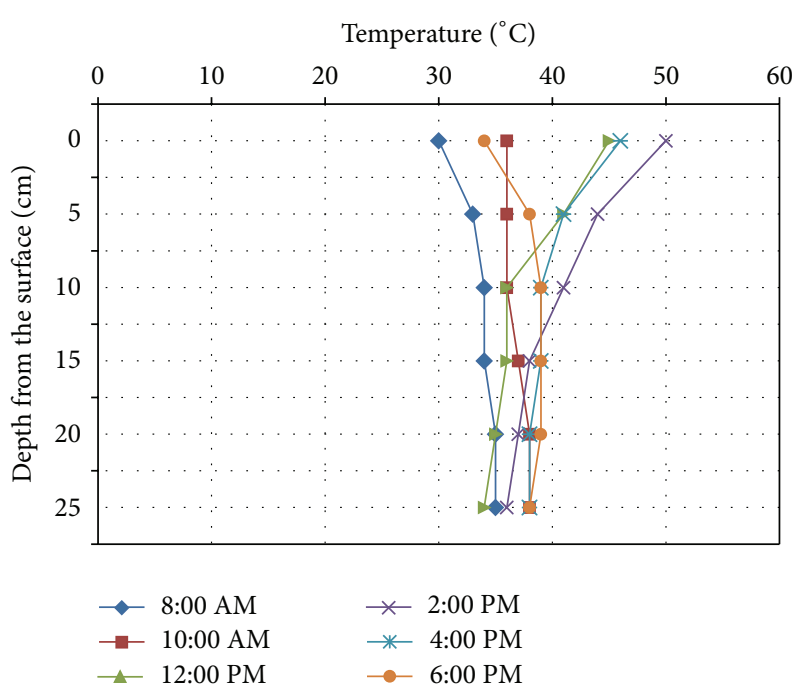

Figure 2: Temperature gradients for standard mixture.

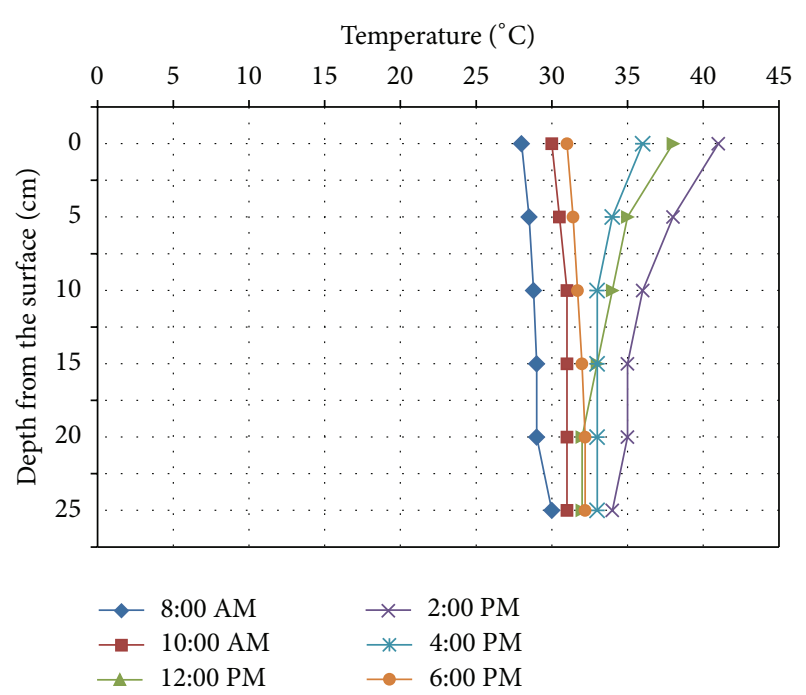

FIgURE 3: Temperature gradients for G20Z0 mixture. 


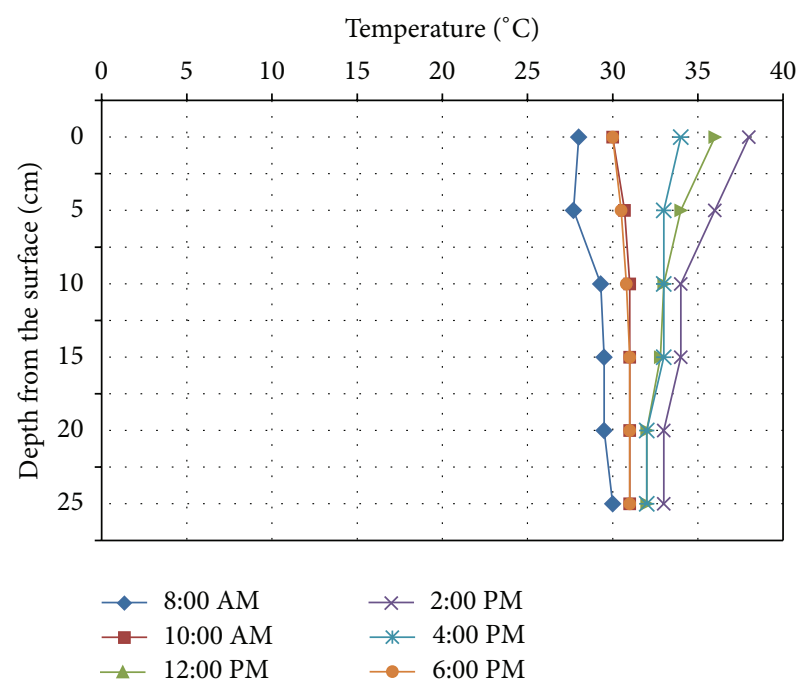

FIGURE 4: Temperature gradients for G20Z30 mixture.

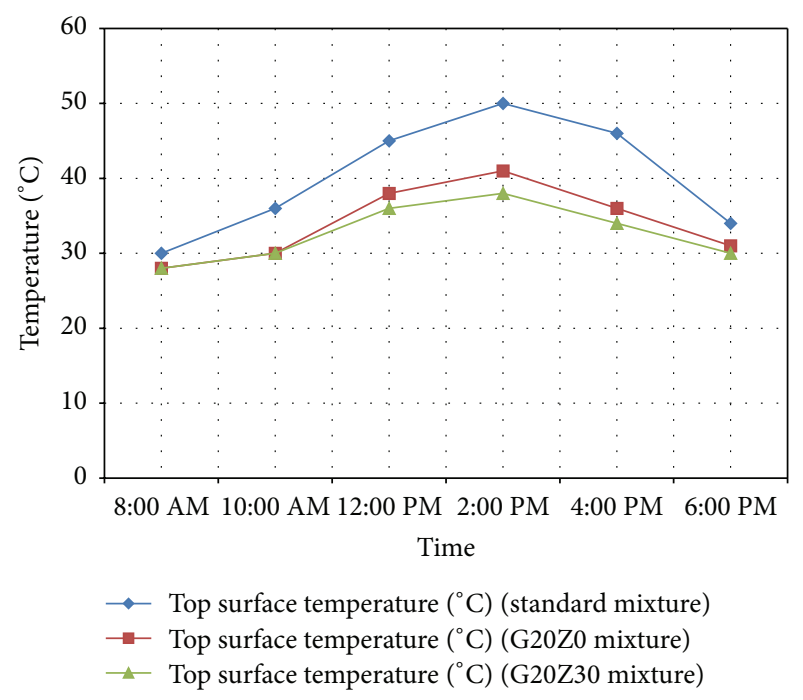

Figure 5: Top surface temperatures of standard mixture, G20Z0 mixture, and G20Z30 mixture.

The reflection coefficient or albedo was not measured by a device in this study. However based on visual observation it was determined that G20Z0 mixture and standard mixture have almost the same surface colour and G20Z30 mixture had a slightly lighter colour than these mixtures (Figure 7). At the end of this study, it was determined that the concrete pavement surface temperature can decrease from $50^{\circ} \mathrm{C}$ to $38^{\circ} \mathrm{C}$ by using G20Z30 type of concrete mixture instead of control mixture and the biggest top and bottom surface temperature difference may decrease from $14^{\circ} \mathrm{C}$ to $5^{\circ} \mathrm{C}$ by this method.

\section{Conclusion}

If the temperature gradient value is high, it is probable to see cracks in concrete roads. Temperature gradients also need to be decreased. This can be done by reducing the pavement surface temperature and thermal conductivity of concrete.

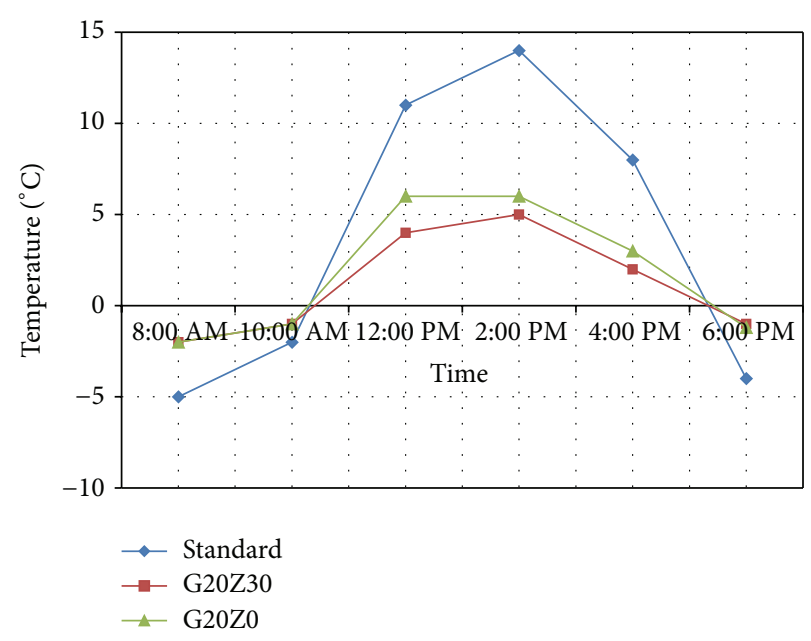

FIGURE 6: Top and bottom surface temperature differences for three samples.

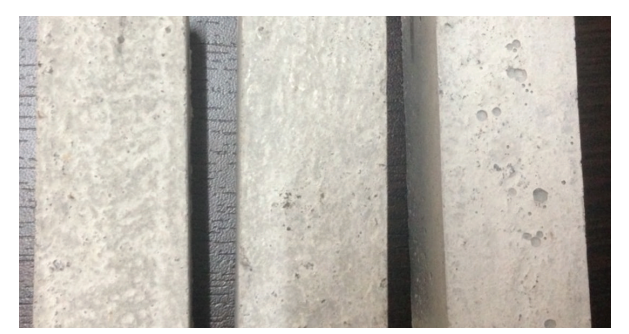

FIGURE 7: Standard mixture sample, G20Z0 sample, and G20Z30 sample, respectively (from left to right).

Reducing the surface temperature also helps to mitigate heat island effect. The first concern of this study was to reduce concrete pavement surface temperature and temperature gradients in concrete while maintaining the concrete strength in the necessary limit during the day in summer.

Aggregates used in this study were limestone. Recycled glass (smaller than $1 \mathrm{~mm}$ ) was used to replace fine aggregate in proportions of $10 \%, 20 \%$, and $30 \%$ by total weight of aggregate. Zeolite replaced Portland cement in proportions of $10 \%$ and $30 \%$ for three different proportions of recycled glass concrete mixtures. ASR measurements were done and all samples met the ASR expansion requirements. Using recycled glass increased the ASR expansions but replacing Portland cement with zeolite in proportion of $30 \%$ decreased these expansions significantly. Compressive strength and flexural strength of all samples were measured at 28 and 90 days. The sample in proportion of $30 \%$ recycled glass as a fine aggregate did not meet the compressive strength requirements whether zeolite was added or not. G30Z0, G30Z10, and G30Z30 mixtures were eliminated for temperature gradient measurements. Temperature gradient measurements were done on concrete slabs for standard mixture, G20Z0 mixture, and G20Z30 mixture between 08:00 AM and 6:00 PM in summer. At the end of this study it was observed that recycled glass (smaller than $1 \mathrm{~mm}$ ) can be used as a fine aggregate up to proportion of $20 \%$ by total weight of aggregate in concrete 
mixtures. Using recycled glass in proportion of $20 \%$ by total weight of aggregate decreases the biggest surface temperature of concrete pavement from $50^{\circ} \mathrm{C}$ to $41^{\circ} \mathrm{C}$. Replacing zeolite with Portland cement in proportion of $30 \%$ in this type of recycled concrete mixture decreases the biggest surface temperature $3^{\circ} \mathrm{C}$ more. Using G20Z0 and G20Z30 mixtures mitigates heat island effect by decreasing surface temperature. The biggest temperature differences between top and bottom surfaces of concrete slab occur at 2:00 PM in summer. These differences are $14^{\circ} \mathrm{C}, 7^{\circ} \mathrm{C}$, and $5^{\circ} \mathrm{C}$ for standard mixture, G20Z0 mixture, and G20Z30 mixture, respectively. G20Z0 and G20Z30 mixtures have smaller temperature gradients in summer and they are good alternative mixtures to prevent thermal cracks.

Recycled glass (smaller than $1 \mathrm{~mm}$ ), which is needed to be used in sustainability, as a fine aggregate and zeolite, which decreases the emission of carbon dioxide released during the production of cement, as Portland cement in concrete, can be used with zeolite in concrete mixture and this mixture is very effective in mitigating heat island and decreasing temperature gradient of concrete pavement.

\section{Competing Interests}

The author declares that there are no competing interests.

\section{Acknowledgments}

This research has been supported by Ondokuz May1s University, under Project no. PYO.MIM.1902.15.001.

\section{References}

[1] H. Akbari and H. D. Matthews, "Global cooling updates: reflective roofs and pavements," Energy and Buildings, vol. 55, pp. 2-6, 2012.

[2] H. Akbari, H. D. Matthews, and D. Seto, "The long-term effect of increasing the albedo of urban areas," Environmental Research Letters, vol. 7, no. 2, Article ID 024004, pp. 1-10, 2012.

[3] H. Li, Evaluation of Cool Pavement Strategies for Heat Island Mitigation in Civil and Environmental Engineering, University of California, Davis, Calif, USA, 2012.

[4] H. Li, J. T. Harvey, T. J. Holland, and M. Kayhanian, "Corrigendum: the use of reflective and permeable pavements as a potential practice for heat island mitigation and stormwater management," Environmental Research Letters, vol. 8, Article ID 015023, pp. 1-14, 2013.

[5] A. Synnefa, T. Karlessi, N. Gaitani, M. Santamouris, D. N. Assimakopoulos, and C. Papakatsikas, "Experimental testing of cool colored thin layer asphalt and estimation of its potential to improve the urban microclimate," Building and Environment, vol. 46, no. 1, pp. 38-44, 2011.

[6] M. Santamouris, A. Synnefa, and T. Karlessi, "Using advanced cool materials in the urban built environment to mitigate heat islands and improve thermal comfort conditions," Solar Energy, vol. 85, no. 12, pp. 3085-3102, 2011.

[7] D. Kolokotsa, P. Maravelaki-Kalaitzaki, S. Papantoniou et al., "Development and analysis of mineral based coatings for buildings and urban structures," Solar Energy, vol. 86, no. 5, pp. 1648-1659, 2012.
[8] A. Deluka-Tibljaš, S. Šurdonja, S. Babić, and M. Cuculić, "Analyses of urban pavement surface temperatures," The Baltic Journal of Road and Bridge Engineering, vol. 10, no. 3, pp. 239246, 2015.

[9] C. Ferrari, A. Muscio, C. Siligardi, and T. Manfredini, "Design of a cool color glaze for solar reflective tile application," Ceramics International, vol. 41, no. 9, pp. 11106-11116, 2015.

[10] C.-M. Kuo, "Effective temperature differential in concrete pavements," Journal of Transportation Engineering, vol. 124, no. 2, pp. 112-122, 1998.

[11] L. J. M. Houben, C. R. Braam, A. J. V. Leest, M. J. A. Stet, J. W. Fréney, and G. Bouquet, "Backgrounds of VENCON2.0 software for the structural design of plain and continuously reinforced pavements," in Proceedings of the 10th International DUT-Workshop on Fundamental Modelling of Design and Performance of Concrete Pavements, pp. 1-20, Old-Turnhout, Belgium, September 2006.

[12] A. G. Heydinger, "Monitoring seasonal instrumentation and modelling climatic effects on pavements at the Ohio/SHRP test road," ODOT Project No. 14704(0), FHWA/OH Report 2003/018, The University of Toledo, Toledo, Ohio, USA, 2003.

[13] Y. H. Huang, Pavement Analysis and Design, Prentice Hall, Upper Saddle River, NJ, USA, 2nd edition, 2004.

[14] K.-H. Kim, S.-E. Jeon, J.-K. Kim, and S. Yang, "An experimental study on thermal conductivity of concrete," Cement and Concrete Research, vol. 33, no. 3, pp. 363-371, 2003.

[15] H. Uysal, R. Demirboga, R. Şahin, and R. Gül, “The effects of different cement dosages, slumps, and pumice aggregate ratios on the thermal conductivity and density of concrete," Cement and Concrete Research, vol. 34, no. 5, pp. 845-848, 2004.

[16] R. Demirboğa and R. Gül, "The effects of expanded perlite aggregate, silica fume and fly ash on the thermal conductivity of lightweight concrete," Cement and Concrete Research, vol. 33, no. 5, pp. 723-727, 2003.

[17] A. H.-C. Shin and U. Kodide, "Thermal conductivity of ternary mixtures for concrete pavements," Cement and Concrete Composites, vol. 34, no. 4, pp. 575-582, 2012.

[18] K. S. Al-Jabri, A. W. Hago, A. S. Al-Nuaimi, and A. H. Al-Saidy, "Concrete blocks for thermal insulation in hot climate," Cement and Concrete Research, vol. 35, no. 8, pp. 1472-1479, 2005.

[19] Y. Xu and D. D. L. Chung, "Effect of sand addition on the specific heat and thermal conductivity of cement," Cement and Concrete Research, vol. 30, no. 1, pp. 59-61, 2000.

[20] C. S. Lam, C. S. Poon, and D. Chan, "Enhancing the performance of pre-cast concrete blocks by incorporating waste glass-ASR consideration," Cement and Concrete Composites, vol. 29, no. 8, pp. 616-625, 2007.

[21] C. Meyer and S. Baxter, "Use of recycled glass for concrete masonry blocks," Final Report 97-15, New York State Energy Research and Development Authority, Albany, NY, USA, 1997.

[22] E. A. Byars, B. Morales-Hernandez, and Z. HuiYing, "Waste glass as concrete aggregate and pozzolan Laboratory and industrial projects," Concrete, vol. 38, no. 1, pp. 41-44, 2004.

[23] R. R. Krishnamoorthy and J. A. Zujip, “Thermal conductivity and microstructure of concrete using recycle glass as a fine aggregate replacement," International Journal of Emerging Technology and Advanced Engineering, vol. 3, no. 8, pp. 463-471, 2013.

[24] M. Najimi, J. Sobhani, B. Ahmadi, and M. Shekarchi, "An experimental study on durability properties of concrete containing zeolite as a highly reactive natural pozzolan," Construction and Building Materials, vol. 35, pp. 1023-1033, 2012. 
[25] C. S. Poon, L. Lam, S. C. Kou, and Z. S. Lin, "A study on the hydration rate of natural zeolite blended cement pastes," Construction and Building Materials, vol. 13, no. 8, pp. 427-432, 1999.

[26] S. Y. N. Chan and X. Ji, "Comparative study of the initial surface absorption and chloride diffusion of high performance zeolite, silica fume and PFA concretes," Cement and Concrete Composites, vol. 21, no. 4, pp. 293-300, 1999.

[27] Ş. Kılınçarslan, "Thermo-mechanical properties of concrete containing zeolite," Suleyman Demirel Universitesi Fen Bilimleri Enstitusu Dergisi, vol. 11, no. 3, pp. 262-267, 2007.

[28] Y. Qin and J. E. Hiller, "Modeling the temperature and stress distributions in rigid pavements: impact of solar radiation absorption and heat history development," KSCE Journal of Civil Engineering, vol. 15, no. 8, pp. 1361-1371, 2011.

[29] E. B. Pancar and M. V. Akpinar, "Temperature reduction of concrete pavement using glass bead materials," International Journal of Concrete Structures and Materials, vol. 10, no. 1, pp. 39-46, 2016.

[30] ASTM C1260, Standard Test Method for Potential Alkali Reactivity of Aggregates (Mortar-Bar Method), Annual Books of ASTM Standards, West Conshohocken, Pa, USA, 2001. 

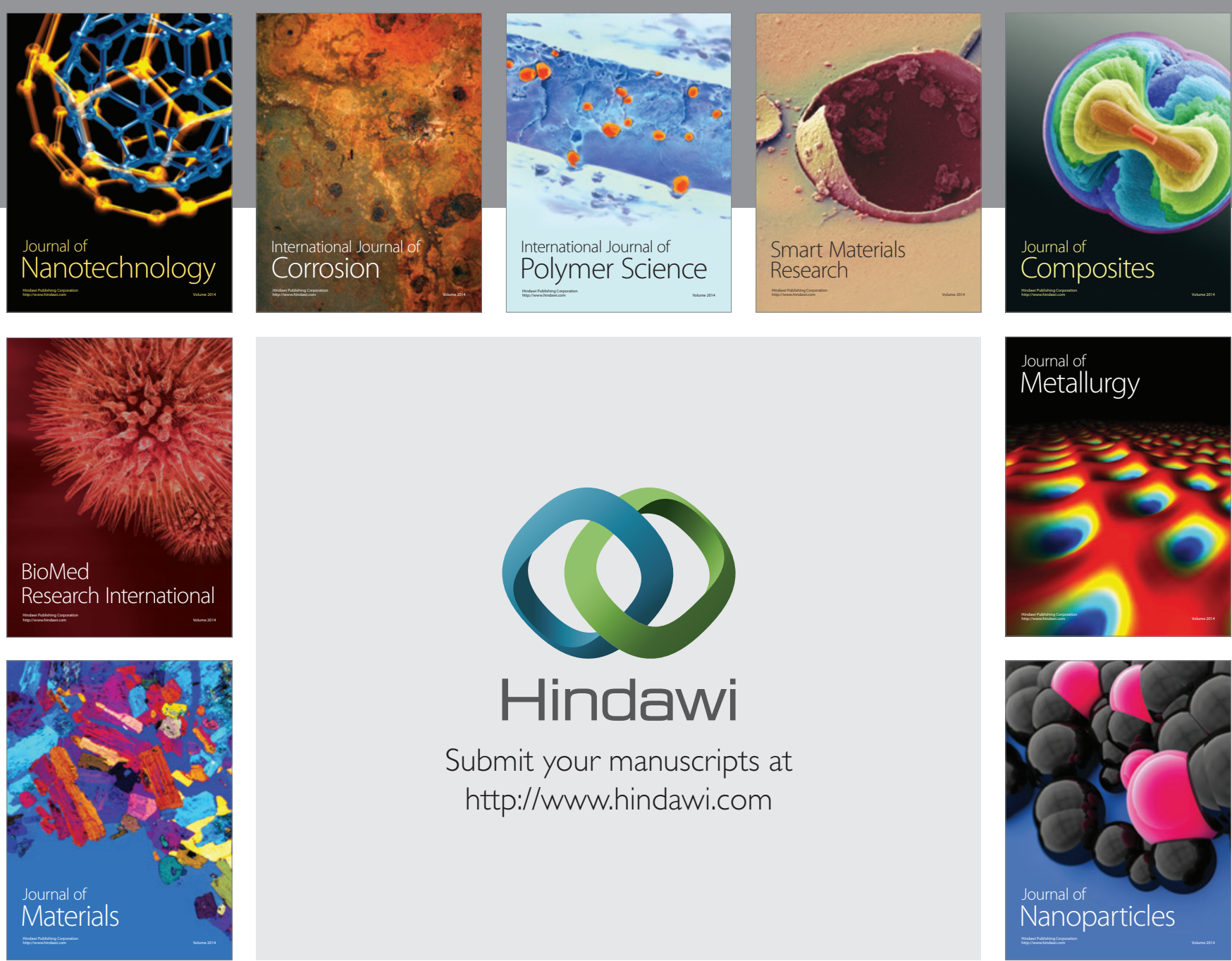

\section{Hindawi}

Submit your manuscripts at

http://www.hindawi.com

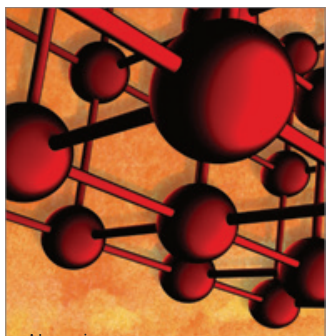

Materials Science and Engineering
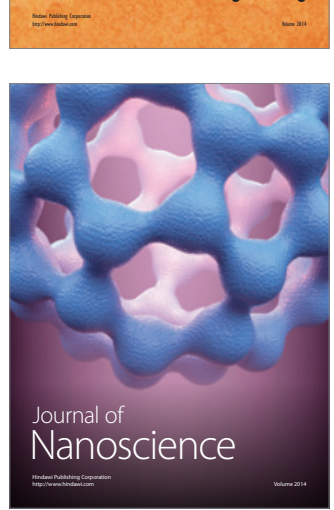
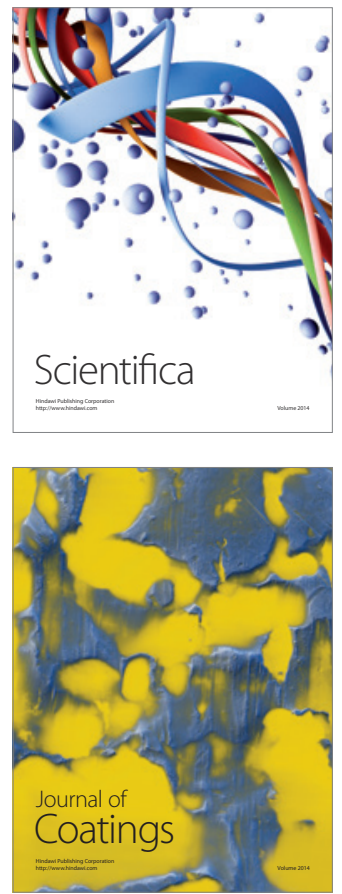
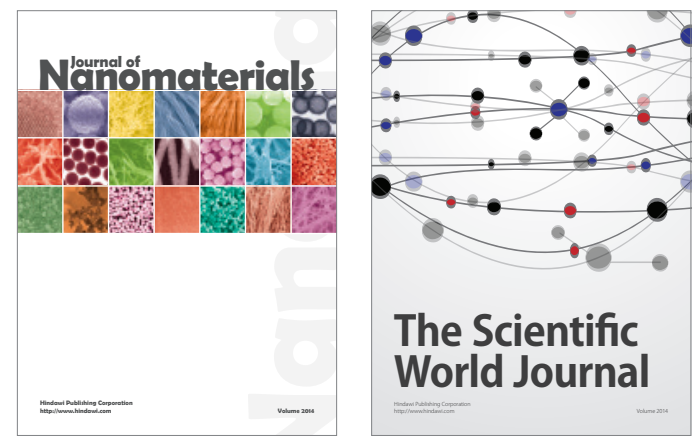

The Scientific World Journal
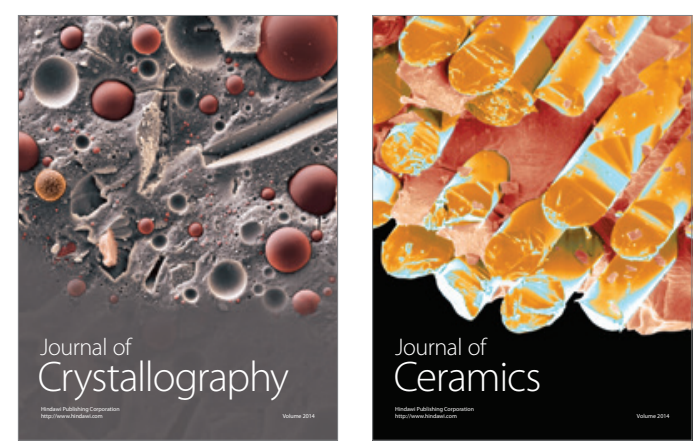
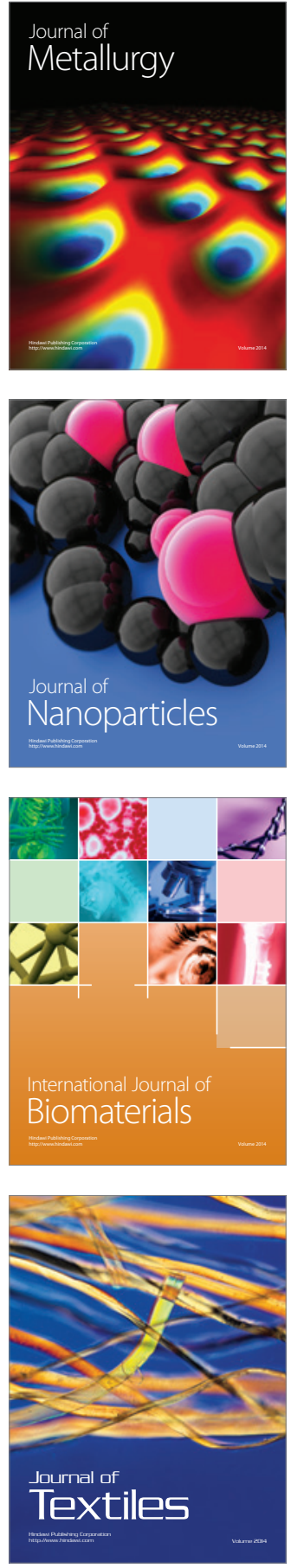